\title{
FANTASY: O HERDEIRO MAINSTREAM DO FANTÁSTICO-MARAVILHOSO
}

\section{FERNANDA DA CUNHA CORREIA*}

Universidade Presbiteriana Mackenzie (UPM), Programa de Pós-Graduação em Letras (PPGL), São Paulo, SP, Brasil.

Recebido em: 22 jan. 2021. Aprovado em: 17 fev. 2021.

Como citar este artigo: CORREIA, F. da C. Fantasy: o herdeiro mainstream do fantástico-maravilhoso. Cadernos de Pós-Graduação em Letras, v. 21, n. 1, p. 135-151, jan./abr. 2021. doi: 10.5935/cadernosletras. v21n1p135-151

\section{Resumo}

A fantasia, ou o fantasy, é um gênero literário que tem sua origem no fantástico tradicional e no maravilhoso, e, na definição clássica de Todorov, o maravilhoso é o fantástico aceito. Tanto o fantástico quanto a fantasia enfrentam alguma resistência do público leitor por conta do insólito existente nas narrativas que obrigam o leitor a romper com a realidade de alguma maneira. A fantasia apresenta uma complexidade causada pela necessidade de criar mundos complexos e exigir ainda mais suspensão da realidade, no entanto, seus leitores e fãs entendem tais demandas como os principais atrativos das histórias e transformaram a fantasia em um fenômeno de público na atualidade.

* E-mail: fernandaccorreia@gmail.com.

(D) https://orcid.org/0000-0003-0158-037X 


\section{Palavras-chave}

Fantasia. Fantasia imersiva. Fandom.

O fantástico permeia as histórias produzidas pela humanidade desde que o homem começou a contar histórias. As mitologias e lendas dos folclores são sempre permeadas de magia e acontecimentos insólitos, ${ }^{1}$ mas foi apenas no século XIV que o fantástico começou a se caracterizar como um gênero por si próprio e, somente no século XX, passou a ser estudado como tal. Tzvetan Todorov (2010), em seu Introdução à literatura fantástica, organizou e estruturou o fantástico. Para o estudioso:

O fantástico ocupa o tempo desta incerteza. Assim que se escolhe uma das duas respostas, deixa-se o terreno do fantástico para entrar em um gênero vizinho: o estranho ou o maravilhoso. 0 fantástico é a vacilação experimentada por um ser que não conhece mais que as leis naturais, frente a um acontecimento aparentemente sobrenatural (TODOROV, 2010, p. 31).

Assim, o fantástico puro é aquele que mantém a incerteza, quando não sabemos quem ou o que é o responsável pelos eventos fora do comum. Quando é explicado, temos o estranho; quando é aceito como parte normal do mundo, temos o maravilhoso. Esses gêneros vizinhos, como chama Todorov (2010), vão se expandir e darão origem a dois outros tipos: a ficção científica e o fantasy.

Partindo do estranho, que tem o fantástico explicado, temos a ficção científica, dividida entre hard, cujos eventos insólitos são explicados pela ciência, e soft ${ }^{2}$ que admite a presença de tecnologias avançadas que não existem, mas que se baseiam em teorias científicas reais, podendo ser criadas na realidade. No outro extremo, temos o maravilhoso, o fantástico aceito dos contos de fadas, que dará origem ao fantasy, com mundos paralelos em que vivem criaturas dos mais diversos tipos.

Apesar de terem sido considerados histórias infantis com o passar do tempo, os contos de fadas têm origem em contos populares e, algumas vezes,

1 Tais histórias não eram necessariamente vistas como narrativas inventadas ou eventos considerados insólitos aos contemporâneos, mas o leitor moderno as vê assim.

2 Hard science fiction e soft science fiction: duas categorizações modernas da ficção científica - a primeira quando a ciência tratada na história pertence ao campo da física, química ou biologia; a segunda quando a ciência pertence ao campo das humanidades. 
podem estar relacionados à mitologia. Em seu ensaio "Sobre estórias de fadas", publicado na coletânea Árvore e folha, Tolkien (2020a) debate o que são histórias de fadas e qual a sua utilidade. Segundo o escritor e filólogo, há uma confusão do termo fada, ou fairy em inglês, com o termo Feéria, ou Faërie no original. $\mathrm{O}$ primeiro diz respeito ao ser diminuto que conhecemos como fada, enquanto o segundo seria o Reino Perigoso que esses seres habitam, com ogros, bruxas, dragões, gigantes, entre outros, e que o ser humano visita nesses contos. Assim, as histórias seriam sobre o reino e não sobre as criaturas que nele habitam.

Feéria seria um mundo à parte, paralelo ao nosso, muito parecido em constituição, mas que tem, entre suas características, a magia como algo natural, principalmente porque a magia desses seres está ligada à natureza. Tolkien (2020a) considera que sobrenaturais são os seres humanos que participam dos contos, porque estão além da natureza mágica desses seres. O que teríamos seria apenas um vislumbre desse Reino Perigoso, com o qual temos contato a partir das histórias, e ele seria muito maior e mais vasto.

Muito parecido com o que Todorov vai considerar como uma história do maravilhoso, Tolkien (2020a, p. 24) define as narrativas sobre fadas e seu reino como:

A definição de uma estória de fadas - o que é, ou o que deveria ser - não depende, então, de qualquer definição ou relato histórico sobre elfos ou fadas, mas da natureza de Feéria: o próprio Reino Perigoso e o ar que sopra naquele país. Não tentarei defini-lo, ou descrevê-lo diretamente. Isso não pode ser feito. Feéria não pode ser capturada numa rede de palavras, pois é uma de suas qualidades ser indescritível, embora não imperceptível. Ela tem muitos ingredientes, mas a análise não necessariamente revelará o segredo do todo. Contudo, espero que o que tenho depois a dizer sobre as outras questões traga alguns vislumbres da minha própria visão imperfeita dela. Para o momento direi apenas isto: uma "estória de fadas" é aquela que aborda ou usa Feéria, qualquer que possa ser seu próprio propósito central: sátira, aventura, moralidade, fantasia. A própria Feéria talvez possa ser traduzida mais aproximadamente por Magia - mas é magia de um ânimo e poder peculiares, no polo oposto ao dos artifícios vulgares do mágico laborioso e científico. Há um único pré-requisito: se houver algo de sátira presente na estória, de uma coisa não se pode zombar - da magia em si. Essa deve, naquela estória, ser levada a sério, não sendo ridicularizada nem explicada. 
Para Tolkien (2020a), as estórias de fadas são narrativas como outras quaisquer, mas, por tratarem de magia e do Reino Perigoso, foram relegadas ao quarto das crianças, deixadas de lado em favor de outros assuntos "mais sérios" ou "mais realistas" das narrativas para adultos. Em seus textos literários, Tolkien vai resgatar essa ideia de um mundo onde a magia é possível e deve ser levada a sério, criando um mundo secundário que permite uma mescla dos dois mundos, o real e o fantasioso. Com isso, partindo do maravilhoso, o escritor dará origem ao gênero fantasy, ou, como chamaremos de agora em diante, à fantasia.

A fantasia vai apresentar um funcionamento muito parecido com o conto de fadas, levando o personagem principal ou o leitor para um mundo completamente novo, regido por regras próprias. No entanto, é preciso que algo aconteça para que o protagonista da narrativa dê início à sua peripécia aristotélica, tal como em qualquer outra narrativa. No entanto, na fantasia, a peripécia pode ou não acontecer a partir do fantástico.

Teóricos do fantástico contemporâneo, que em sua maioria lidam com o insólito no cotidiano de nossa vida moderna, levam em consideração a importância do que chamam de transgressão para que haja o fantástico, ou seja, é preciso um evento que identifique quando o fantástico invade o mundo real e cria a narrativa. É preciso que a normalidade seja rompida pelo evento insólito para que ela seja uma narrativa do fantástico. Para David Roas (2014, p. 44-45),

Mas que transgressão pode estabelecer o mundo dos contos de fadas ou um mundo como o que Tolkien criou? O lugar em que transcorrem as ações de 0 senhor dos anéis não tem nada a ver com o funcionamento físico do nosso mundo, do que se deduz que nada do que ali aconteça pode ser sentido como ameaçador para a estabilidade de nossa realidade. Porque, em última instância, não é nossa realidade, e sim um mundo autônomo, independente dela. 0 leitor do romance de Tolkien se sabe diante de um mundo absolutamente irreal, onde tudo é admissível, e onde, portanto, não existe possibilidade de transgressão.

No entanto, podemos questionar se realmente não há uma transgressão proporcional nas histórias da fantasia. Partindo do mesmo ponto de Roas, realmente não há espaço para tal acontecimento, afinal, a maior ruptura acontece ao leitor que, ao iniciar o romance de fantasia e decidir por continuá-lo, adentra em uma história constrói um mundo novo para abarcar a trama. Ainda 
assim, não é possível afirmar que não existe possibilidade de transgressão porque nesses Mundos Secundários tudo é admissível.

Podemos observar alguns pontos de semelhança com o mundo primário, afinal, depois do estranhamento de ser apresentado a um hobbit, o leitor da história de Bilbo Bolseiro logo reconhece o comportamento do protagonista como o seu próprio, um sujeito comum e pacato que não deseja pessoas estranhas invadindo sua casa na hora do chá. Não é muito diferente do que Roas (2014, p. 110) define como "O mundo construído nos contos fantásticos é sempre um mundo em que de início tudo é normal e que o leitor identifica com sua própria realidade", e o que muda na fantasia é que não são as imagens que vão criar a identificação, mas o comportamento dos personagens.

Toda e qualquer narrativa cria um Mundo Secundário, por mais realista que seja seu autor. Ainda há uma criação literária e estética em andamento, que pressupõe um leitor com um certo tipo de referências. Não podemos pressupor que um texto do século XV não pareça fantástico a um leitor do século XXI, narrativas de viagens, por exemplo, descreviam lugares até então considerados exóticos como verdadeiros mundos à parte. Ainda hoje, um costume rotineiro do Leste Europeu pode parecer insólito a um latino-americano e vice-versa. O que muda é a postura do leitor ao iniciar a leitura, procurando pistas para firmar a identificação.

As narrativas propõem, ao serem iniciadas, pactos de realidade com seus leitores. Conforme a leitura avança e o texto apresenta lugares reais, muitas vezes conhecidos do leitor, o pacto mais se aproxima do real. Nesse caso, a transgressão do fantástico é mais intensa porque ela rompe com o pacto narrativo acordado até então. Por isso, alguns leitores não se agradam desses tipos de texto, porque não gostam de ser surpreendidos. O pacto de leitura é o que vai definir a "consistência interna da realidade", ou seja, aquilo que pode ou não pode acontecer. Tolkien (2020a, p. 58) vai dizer que, qualquer que seja a narrativa, é a parte mais difícil de contar histórias, sendo para a fantasia ainda mais complicado:

Mas o erro ou a maldade, engendrados pela inquietação e pelo consequente desgosto, não são a única causa dessa confusão. A Fantasia tem também uma desvantagem essencial: é difícil de ser alcançada. A Fantasia pode ser, como eu acho, não menos, mas mais subcriativa; mas, de qualquer modo, descobre-se, na prática, que a "consistência interna da realidade" é tão mais difícil de produzir quanto mais diferentes forem as imagens e os rearranjos de material primá- 
rio em relação ao arranjos reais do Mundo Primário. É mais fácil produzir esse tipo de "realidade" com material mais "sóbrio".

A fantasia exige um pacto de realidade mais complexo porque o mundo narrado é inteiro novo e não pode abrir contradições. É preciso que aquela trama seja crível, o que é muito mais fácil quando o texto está ancorado na realidade e o leitor pode acessar suas próprias memórias e seu próprio conhecimento de mundo para construir mentalmente o espaço descrito pelo autor. Por isso o impacto do fantástico contemporâneo é tão grande para leitores contemporâneos, a "consistência interna da realidade" é abalada e deve ser muito bem-feita para que seja crível, mesmo que insólita ou absurda. A complexidade da fantasia está no fato de o autor precisar guiar o leitor na construção desse mundo, deixando bem claro quais as regras e como funcionam as leis desse lugar.

Se um texto que parte do mundo real se passar no Japão, é crível que seja dito que pessoas não se cumprimentam com beijos no rosto como no Brasil, dessa forma, leitores brasileiros terão, pelo menos uma, se não as duas, referências. No caso da fantasia, se é dito que não é possível alterar o espaço-tempo a partir do uso de magia, então, a solução narrativa não pode ser uma viagem no tempo porque isso foi acordado com o leitor anteriormente. Como explica Tolkien (2020a, p. 58),

A Fantasia, é claro, começa com uma vantagem: estranheza arrebatadora. Mas essa vantagem foi voltada contra ela e contribuiu para sua difamação. Muitas pessoas não gostam de ser arrebatadas. Não gostam de qualquer interferência no Mundo Primário, ou naqueles pequenos vislumbres dele que são familiares a elas.

O escritor completa, em seu ensaio, dizendo que a fantasia exige uma "consistência interna da realidade" maior e questiona se o fato de os contos de fadas e, por consequência, as histórias de fantasia serem relacionados às crianças se deve ao fato de elas terem menos referencial que os adultos e poderem ser "melhor enganadas":

As crianças são capazes, é claro, de crença literária, quando a arte do criador de estórias é boa o suficiente para produzi-la. Esse estado da mente tem sido chamado de "suspensão voluntária da descrença". Mas isso não me parece uma boa descrição do que acontece. 0 que realmente acontece é que o criador 
de estórias mostra ser um "subcriador" bem-sucedido. Ele cria um Mundo Secundário que a sua mente pode adentrar. Dentro dele, o que relata é "verdadeiro", está de acordo com as leis daquele mundo. Você, portanto, acredita, enquanto está, de certa forma, ali dentro. No momento em que a descrença surge, o feitiço se quebra; a magia, ou melhor, a arte, falhou. Você, então, sai para o Mundo Primário de novo, olhando para o pequeno e abortivo Mundo Secundário do lado de fora. Se você for obrigado, por bondade ou circunstância, a ficar, então a descrença tem de ser suspensa (ou abafada); do contrário, ouvir e olhar se tornariam intoleráveis. Mas essa suspensão da descrença é um substituto da coisa genuína, um subterfúgio que usamos quando condescendemos a jogos ou faz de conta ou quando tentamos (mais ou menos, voluntariamente) achar a virtude que pudermos numa obra de arte que, para nós, fracassou. Um verdadeiro entusiasta do críquete está no estado encantado: Crença Secundária. Eu, quando vejo uma partida, estou no nível inferior. Consigo atingir uma suspensão voluntária da descrença, quando estou preso lá e apoiado por algum outro motivo que mantenha o tédio a distância: por exemplo, uma preferência selvagem, heráldica, por azul-escuro em vez de azul-claro. Essa suspensão da descrença pode, assim, ser um estado algo cansado, desmazelado ou sentimental da mente e, portanto, inclinar-se para o "adulto". Imagino que esse seja frequentemente o estado dos adultos na presença de uma estória de fadas. Eles são mantidos ali e apoiados por sentimentos (memórias da infância, ou noções de como a infância deveria ser); acham que deveriam gostar da estória. Mas, se realmente gostassem dela, por si mesma, não teriam de suspender a descrença: eles acreditariam - nesse sentido (TOLKIEN, 2020a, p. 47-48, grifo do autor).

Assim, o autor de fantasia precisa ser ainda mais cuidadoso porque, se as leis internas que ele criou para seu Mundo Secundário não se sustentarem, toda a sua história não se sustentará. O texto de fantasia não pode narrar sobre um mundo em que qualquer coisa pode acontecer, pois a narrativa precisa de linhas definidas e claras, possibilitando ao leitor acompanhar e realmente se sentir parte do mundo narrado.

A fantasia pode ser feita de diversas formas, podendo utilizar algumas regras do mundo real para que se sustente. Farah Mendlesohn (2008, p. 21) apresenta a divisão do gênero em quatro categorias: de portal, imersiva, intrusiva e umbral. Esta última categoria estaria mais relacionada ao estranho da definição tradicional de Todorov, enquanto as outras são mais próximas do maravilhoso. Assim, Matangrano e Tavares (2019, p. 234), citando Nogueira Filho (2013, p. 67), dividem a fantasia em três categorias: imersiva, de portal e intrusiva.

141 
A fantasia intrusiva é aquela na qual o mundo fantástico, que existe em paralelo ao mundo do leitor, invade a realidade, e assim a história se passa em cenários conhecidos. Como exemplos temos a maioria dos livros de Neil Gaiman e a série Percy Jackson, na qual jovens descobrem-se semideuses como na mitologia grega e precisam lidar com figuras mitológicas nos Estados Unidos de atualmente. A fantasia de portal inverte a ideia anterior: a história começa no mundo real e, após a passagem por um portal, um novo mundo se apresenta ao protagonista. Como exemplos temos a série Harry Potter, na qual o mundo bruxo existe em completo paralelo com o mundo comum e é preciso ter conhecimento mágico para acessá-lo, e a mais famosa fantasia de portal, As crônicas de Nárnia, em cujos livros as crianças partem do Mundo Primário conhecido para o mundo mágico de Nárnia.

As obras de Tolkien já mencionadas são exemplos da fantasia imersiva, na qual o leitor precisa deixar para trás quase todo conhecimento de mundo que possui e adentrar um novo universo criado pelo autor. Por isso, Tolkien considerava que existem muitas pessoas que não gostam do tipo histórias que ele produzia, porque tais leituras necessitam de um pacto com uma nova realidade, descoberta enquanto se lê. O gênero da fantasia imersiva não foi inaugurado pelas obras da Terra-média. Segundo Mantagrano e Tavares (2019, p. 244), os primeiros livros do tipo foram publicados por George McDonald, autor de $A$ princesa e o goblin (1872), e William Morris, autor de O bosque além do mundo (1892). No entanto, foram as obras de Tolkien que moldaram o que se tornou o expoente da fantasia como um todo, influenciando diversos autores do gênero que vieram posteriormente, como George R. R. Martin.

De modo geral, mais do que a existência de um outro mundo diferente do mundo real, o que caracteriza o gênero da fantasia é a construção de sagas. Não é possível produzir um texto de fantasia, de qualquer um dos três tipos, em um texto curto ou novela porque é necessário apresentar ao leitor esse novo mundo, o que requer tempo e texto. Mas, principalmente, porque a construção de uma história de fantasia pressupõe uma mitopoese, ou seja, a construção de mitos. No caso das fantasias imersivas, geralmente os mitos criados abarcam desde uma cosmogonia até um apocalipse. Há histórias e lendas próprias, das quais os personagens ouviram falar e estão acostumados a tratar como mitos.

A transgressão na fantasia imersiva geralmente ocorre a partir dessa mitologia própria, apresentada com o mundo novo ao leitor como um mito ou uma 
história infantil contada aos personagens. Em O senhor dos anéis, quando descobrimos que o anel mágico é, na realidade, o Um Anel, somos apresentados à história de um Senhor do Escuro que teria presenteado com anéis mágicos que ele poderia controlar a elfos, homens e anãos. Para Frodo, personagem que escuta a revelação, tudo não passava de um mito e histórias que seu tio contava, mas que acabam se provando reais.

Em As crônicas de gelo e fogo, nós temos os dragões e os caminhantes brancos que pertenciam a um passado remoto e surgem em meio à trama como ameaças reais. Pensando em um exemplo do cinema, Star Wars apresenta inicialmente os jedi como membros de uma religião antiga que desapareceram e ninguém mais acredita na possibilidade de manipular a Força. A existência dos jedi e da Força vão se provar verdadeiros e formar uma parte central da história: o treinamento de Luke como um jedi. Todas as histórias apresentam o padrão de introduzir lendas e histórias que depois vão se provar reais. Quanto mais bem estabelecida essa mitologia própria, mais convincente é o ressurgimento da magia e o espanto dos personagens com isso.

Todas essas histórias de fantasia imersiva têm em comum características que as aproximam do fantástico-maravilhoso. Assim como os contos de fadas, há uma moldura para introduzir a história, um “Era uma vez...”. No entanto, ele não evoca as imagens dos contos tradicionais, e, assim como a floresta de Lórien na Terra-média, o leitor encontra o que levar consigo, seja bom ou seja mau:

O clássico mundo maravilhoso, explicitado na forma do "era uma vez" dos contos de fada, se redimensionou em novas construções narrativas que provocaram os leitores a experimentar possibilidades de compreensão do real, marcadas pelo universo imaginativo do medo, da dúvida e das ambiguidades. A literatura foi invadida por fantasmas, mortos vivos, vampiros e lobisomens, criaturas fantásticas que significaram a força motriz da literatura fantástica do século XIX com suas nuances de incerteza e dubiedade. No século XX, estas figuras monstruosas também se reconfiguram, e o monstro deixa de ser exterior ao homem, não está mais escondido ou envolto em brumas ou mansões mal-assombradas. 0 monstruoso agora habita a interiordade dos sujeitos, traduz-se em marcas no seu corpo e o homem surge, a partir de alguns relatos fantásticos do século XX, como a própria imanência do fantástico (ATIK; TREVISAN, 2019, p. 64).

No caso de O hobbit, a primeira frase do romance, "Numa toca no chão vivia um hobbit”, já apresenta ao leitor que ele está entrando em um mundo 
diferente, de forma normalizada. Da mesma forma, os filmes de Star Wars sempre iniciam com o letreiro "A long time ago in a galaxy, far far away...", também já indicando o que o espectador irá adentrar em um mundo de fantasia.

Assim como os contos de fadas, essas histórias também terminam bem. Geralmente, os contos terminam com um "E viveram felizes para sempre", final com o qual Tolkien (2020a, p. 87) não concordava:

\begin{abstract}
O final verbal - normalmente considerado algo tão típico do fim das estórias de fadas quanto "era uma vez" é do começo - "e eles viveram felizes para sempre" é uma tática artificial. Não engana ninguém. Frases finais desse tipo devem ser comparadas às margens e molduras de pinturas e não devem ser pensadas como o final verdadeiro de qualquer fragmento particular da inconsútil Teia da Estória, mais do que a moldura é o final da cena visionária, ou um estojo abrange o Mundo Exterior.
\end{abstract}

O problema, para Tolkien (2020a), é que os contos são apenas recortes de acontecimentos de todo o Reino Perigoso, que não teria como, assim como o mundo real, realmente "viver feliz para sempre". Outras histórias e acontecimentos viriam desestabilizar o equilíbrio e iniciar uma nova aventura, que poderia ser contada ou não. Ou seja, o que incomodava Tolkien era a moldura colocada nas histórias, não o final feliz em si. O autor considerava que as suas histórias deveriam acabar bem, porque a história humana um dia acabará bem, quando alcançar o Paraíso. Então, essas histórias de fantasia imersiva também têm em comum a característica de acabar com uma eucatástrofe, termo cunhado por Tolkien. Seria uma catástrofe, uma mudança grande e permanente em seus limites, mas positiva. Assim, temos a vitória do bem contra o mal em $O$ senhor dos anéis, mas não sem consequências, seus personagens ficaram marcados pelo mal que enfrentaram, da mesma forma que Luke vence o Imperador por conta da redenção final de Darth Vader, mas Vader morre e Luke tem que lidar com a morte do pai e a perda de uma mão.

Por se tratar de narrativas extensas, as fantasias imersivas muitas vezes modalizam outros gêneros dentro de suas histórias. É possível encontrar momentos de comédia, romance, terror e, em certa medida, fantástico em suas histórias. A passagem da Comitiva do Anel por Moria ou a travessia de Frodo e Sam pela toca da Laracna em Mordor evocam momentos de terror e remetem aos romances góticos. Assim, como o encontro de Merry e Pippin com os Ents se aproxima do fantástico porque, até então na narrativa, árvores eram 
árvores e a história dos Ents foi esquecida conforme eles diminuíram em número, ou o encontro da Comitiva com a senhora Galadriel, sobre a qual ouviram histórias como se ela fosse uma das rainhas das fadas de nossos contos tradicionais.

No entanto, o leitor precisa de alguma coisa em que se apoiar na narrativa para se envolver com a trama. No fantástico, isso geralmente acontece por conta da familiaridade com situações rotineiras apresentadas antes do insólito acontecer ou pelos personagens humanos com problemas comuns. No caso da fantasia, especialmente a imersiva, a familiaridade acontece pela metafísica. A metafísica é o ramo da filosofia que se preocupa com a existência do ser, buscando a significação da realidade e da vida humana.

Assim, por mais diferentes dos humanos que sejam os personagens fantasiosos, suas ações e comportamentos correspondem a ações humanas comuns, com as quais o leitor pode se identificar e, assim, estabelecer o pacto de realidade. Ainda nas obras de Tolkien, os grandes temas são a efemeridade da vida e a busca desenfreada pelo poder, temas perfeitamente humanos e atuais. Além disso, os personagens são movidos por valores como coragem, amizade e altruísmo. Os eventos que desestabilizam a organização do Mundo Secundário, em geral, vão romper com tais valores.

Como explicam Atik e Trevisan (2019, p. 21), “Tanto criar, como ler as imagens do insólito, significa vivenciar diferentes experiências cognitivas, nas quais o mundo do insólito é o mundo, por essência, construído em diálogo em diálogo com o contexto da sua produção e em diálogo com o tempo da sua recepção". Tendo sido escrita à época dos grandes conflitos do século XX, podemos compreender a importância desses temas nas tramas das obras de Tolkien e o fascínio exercido por eles no leitor, que não os encontrava na realidade em conflito. Da mesma forma, a obra de George R. R. Martin apresenta personagens com protagonismo cuja moral é duvidosa, não podendo se confiar em nenhum deles, apresentando tramas de poder e destruição, nas quais, muitas vezes, não há esperanças e a destruição total é iminente. Diferentemente da obra de Tolkien, Martin escreve numa época pós-moderna, desiludida e questionando muitas coisas tidas como certas.

Esse tipo de identificação é relevante por conta da forma como o fã do gênero de fantasia se comporta, dedicando-se de diversas formas ao objeto cultural de que gosta. Como a identificação acontece em um nível mais profundo, muitas vezes de moral e comportamento, ela é muito mais forte. Henry 
Jenkins (2015, p. 286), ao estudar o papel do fã na cultura participativa, afirma o seguinte: "existe algo de fortalecedor no que os fãs fazem com esses textos quando tentam assimilá-los ao particular de sua vida. O fandom exalta não os textos excepcionais, mas sim leituras excepcionais”.

Já na época em que Tolkien lançou seu primeiro livro, nos anos 1930, os fãs entravam em contato com o autor por meio de cartas. Com o passar do tempo, os fãs tornaram-se cada vez mais dedicados, e, com a evolução dos meios de comunicação, o contato com outros fãs que compartilham os mesmos gostos foi facilitado, construindo uma grande comunidade em torno de uma série de livros, filmes ou programas de televisão. O contato virtualizado também facilita o distanciamento, uma vez que as histórias que motivam tal encontro não se passam no mundo real:

\begin{abstract}
0 livro de Michel Serres, Atlas, ilustra o tema do virtual como "não-presença". A imaginação, a memória, o conhecimento, a religião são vetores de virtualização que nos fizeram abandonar a presença muito antes da informatização e das redes digitais. Ao desenvolver esse tema, o autor de Atlas levanta indiretamente, uma polêmica com a filosofia heideggeriana "ser-ai". "Ser-al" é a tradução literal do alemão Dasein que significa, em particular, existência no alemão filosófico clássico e existência propriamente humana - ser um ser humano - em Heidegger. Mas, precisamente, o fato de não pertencer a nenhum lugar, de frequentar um espaço não designável (onde ocorre conversação telefônica?), de ocorrer apenas entre coisas claramente situadas, ou de não estar somente "presente" (como todo ser pensante), nada disso impede a existência. Embora uma etimologia não prove nada, assinalemos que a palavra existir vem precisamente do latim sistere, estar colocado, e do prefixo ex, fora de. Existir é estar presente ou abandonar uma presença? Dasein ou existência? Tudo se passa como se o alemão sublinhasse a atualização e o latim a virtualização (LÉVY, 2017, p. 20-21, grifos do autor).
\end{abstract}

Os fãs do gênero, assim como os fãs de ficção científica, podem passar horas ou dias debatendo temas ou detalhes de suas obras favoritas, sem chegar à conclusão alguma, o que importa para eles é a interação. As antigas listas de endereço para troca de carta foram substituídas por fóruns on-line e, atualmente, por redes sociais, nas quais pessoas com interesses em comum podem entrar em contato umas com as outras. Nesses ambientes virtuais, discutem-se qual o personagem favorito, adaptações para outras mídias, caracterizações de 
personagens, dicas para produção de cosplay, ${ }^{3}$ troca de fanfics ${ }^{4}$ e todo tipo de material produzido por fãs.

Cada vez que o fã retrabalha os textos da forma que melhor agrade ao seu gosto pessoal, trata-se de uma nova leitura, o que dá sobrevida ao texto:

A leitura fã, contudo, é um processo social através do qual interpretações pessoais são moldadas e reforçadas através de discussões constantes com outros leitores. Tais discussões ampliam a experiência do texto, que supera seu consumo inicial (JENKINS, 2015, p. 62).

Esses grupos passaram a se organizar presencialmente em eventos regulares e convenções, nos quais, além da interação de pessoas que se conheceram a partir de plataformas virtuais, há competições, apresentações de arte, venda de produtos colecionáveis e de produção própria dos fãs, trocas de material, jogos e debates a respeito das obras que os levaram até lá. Algumas pessoas viajam para os locais onde os encontros estão acontecendo e aqueles que são itinerantes têm fãs que os acompanham a cada novo endereço. Aos poucos, as organizações se profissionalizaram, com fãs criando empresas responsáveis para organizar outros eventos com o mesmo modelo, mas de diferente temática.

Tais movimentações de fãs chamaram a atenção das empresas responsáveis pelos produtos culturais admirados pelas pessoas, e os donos dos direitos passaram a se articular com os fã-clubes para assumir o controle desses encontros, dessa vez tidos como oficiais, facilitando a participação de atores e escritores. Editoras e produtoras perceberam o potencial e passaram a fazer os eventos amadores trabalharem a seu favor. A Lucasfilm, responsável pelos filmes da saga Star Wars, oficializou o encontro de fãs conhecido como JediCon. Uma das atividades que ocorrem nesses eventos é a construção de robôs como os que são vistos nos filmes, e um fã foi contratado pela produtora para construir os novos modelos deles quando a franquia passou a se expandir (BURTON, 2020).

Os fãs deixaram de ser meros consumidores e passaram a ser produtores, tornando-se parte importante da organização e sendo levados em considera-

3 O cosplay é o ato de se vestir como um personagem fictício com a maior riqueza de detalhes possível, havendo até mesmo concursos para escolher as melhores criações. Fãs dedicam meses de trabalho para produzir fantasias que se assemelham aos personagens.

4 Ficção de fã, hábito que existe há muito tempo, mas que ganhou força com a internet pela facilidade de edição e distribuição de materiais. A ficção de fã pode ser uma continuação da história a partir de onde o autor finalizou, uma completa releitura da obra original ou apenas modificações de partes da obra original. Além de texto, podem-se produzir ilustrações, filmes e músicas. 
ção no momento de tomar decisões comerciais. Fóruns são consultados por estúdios e editoras para lançar novos produtos ou repaginar aqueles que já são conhecidos. Perfis de possíveis consumidores também são traçados, podendo definir se eles serão o tipo certo de público para um lançamento, e a resposta deles também é monitorada, fazendo com que mudanças possam ser feitas.

Além do valor comercial direto, esse comportamento fã também permite que histórias continuem sendo distribuídas e encontrem novos fãs a cada nova geração. As histórias não estão presas a um espaço ou a um tempo específicos, produtos continuam sendo consumidos e debatidos 40, 50 anos depois de seu lançamento, ou muito mais tempo. Algo comum a livros, mas inesperado para filmes e séries de televisão.

Quando uma pessoa, uma coletividade, um ato, uma informação se virtualizam, eles se tornam "não-presentes", se desterritorializam. Uma espécie de desengate os separa do espaço físico ou geográfico ordinários e da temporalidade do relógio e do calendário. É verdade que não são totalmente independentes do espaço-tempo de referência, uma vez que devem sempre se inserir em suportes físicos e se atualizar aqui ou alhures, agora ou mais tarde. No entanto, a virtualização Ihes fez tomar a tangente. Recortam o espaço-tempo clássico apenas aqui e ali, escapando a seus lugares comuns "realistas": ubiquidade, simultaneidade, distribuição irradiada ou massivamente paralela. A virtualização submete a narrativa clássica a uma prova rude: unidade de tempo sem unidade de lugar (graças às interações em tempo real por redes eletrônicas, às transmissões ao vivo, aos sistemas de telepresença), continuidade de ação apesar de uma duração descontínua (como na comunicação por secretária eletrônica ou por correio eletrônico). A sincronização substitui a unidade de lugar, e a interconexão, a unidade de tempo. Mas, novamente, nem por isso o virtual é imaginário. Ele produz efeitos. Embora não se saiba onde, a conversação telefônica tem "lugar", veremos de que maneira no capítulo seguinte. Embora não se saiba quando, comunicamo-nos efetivamente por réplicas interpostas na secretária eletrônica. Os operadores mais desterritorializados, mais desatrelados de um enraizamento espaço-temporal preciso, os coletivos mais virtualizados e virtualizantes do mundo contemporâneo são os da tecnociência, das finanças e dos meios de comunicação. São também os que estruturam a realidade social com mais força, e até com mais violência (LÉVY, 2017, p. 21).

O senhor dos anéis não sai da lista de mais vendidos do Reino Unido há anos, e uma série de televisão está em desenvolvimento após o sucesso do seriado que adaptou As crônicas de gelo e fogo. A saga Star Wars, mesmo com crí- 
ticas, continua rentável, e novos produtos, de séries a parques temáticos, continuam sendo anunciados. Como explica Jenkins (2015, p. 226): “a cultura fã é nômade, está em expansão constante, aparenta uma grande e abarcante amplitude, mas, ao mesmo tempo, é permanente, capaz de sustentar fortes tradições e criar obras duradouras". A cultura fã tem um papel importante, demonstrando que essas histórias continuam relevantes e novas pessoas querem continuar visitando esses universos.

A fantasia se emancipou do fantástico e do maravilhoso, tornando-se um gênero próprio e à parte, mas mantém suas raízes nesses textos, podendo retomá-los e reescrevê-los dentro de sua própria narrativa. Entre as diversas vertentes da fantasia, a imersiva é complexa e exige maior atenção do autor para que não existam contradições. Qualquer falha é capaz de quebrar a "magia" e é possível lembrar que não se trata de um mundo real, da mesma que um celular ou um computador em uma história do século XVIII romperia o "pacto de verossimilhança".

Os Mundos Secundários da fantasia precisam que seus leitores se conectem de uma forma peculiar aos textos, fazendo com que a identificação do leitor, normalmente ocorrida após a apresentação de cenários e situações verossimilhantes nas histórias insólitas ou realistas, aconteça em um nível mais profundo. O leitor pode se identificar com a postura e com os valores demonstrados pelos protagonistas. Bravura, coragem e sabedoria geralmente são algumas das características que os heróis vão apresentar, fazendo com que o leitor se relacione, mesmo que não se trate de um ser humano.

A imersão acaba sendo mais do que entrar figurativamente em um mundo imaginário, mas viver as aventuras dos protagonistas como se fossem as suas, colocando à prova tudo o que foi necessário para a identificação com os personagens. $\mathrm{O}$ leitor, mas principalmente o fã, de tais narrativas busca a imersão também no plano do real. $\mathrm{O}$ sucesso das literaturas de fantasia se explica em parte pela possibilidade de criar comunidades de fã que dividem os mesmos interesses.

Além de permitir a manutenção da relevância comercial de livros, filmes e séries, os eventos de fãs são mais do que meras possibilidades de consumir, em diferentes sentidos, os produtos dos quais gostam. Os eventos, mesmo os que consistem em simples encontros de amigos em torno de um tema em comum, são possibilidades de estender a experiência imersiva. O debate sobre os materiais, a criação e revisão ou a releitura deles são momentos nos quais os fãs 
revivem as mesmas sensações que tiverem ao acompanharem os originais. É uma possibilidade de retorno ao Mundo Secundário do qual provavelmente eles não gostariam de sair.

A fantasia bem produzida extrapola os limites de sua própria criação, permitindo que os fãs se apropriem da história e a revivam a partir de diferentes experiências, de modo a possibilitar que o Mundo Secundário se concretize, mesmo que parcialmente, na realidade que todos dividimos.

\section{Fantasy: the fantastic-wonderful mainstream heir}

\section{Abstract}

Fantasy is a literary genre which origin goes back to the traditional fantastic and the wonderful. The wonderful, in the classic definition by Todorov, is the fantastic accepted. Both the traditional fantastic and the wonderful finds some reader's resistance due to the unusual that exists in the fantastic narrative and makes the reader disrupt the reality. The fantasy is even more complex since it needs an entirely new world, build from the author's imagination, and, because of this characteristic, makes the reader even more participative. However, the readers and fans of this genre acknowledge these features and embrace them, understanding that as essential to the experience of reading and making Fantasy a pop culture phenomenon nowadays.

\section{Keywords}

Fantasy. High fantasy. Fandom.

\section{REFERÊNCIAS}

ATIK, M. L. G.; TREVISAN, A. L. Narrativas insólitas ou realidades possíveis. São Paulo: Todas as Musas, 2019.

BURTON, B. R2-D2 fan builders hired for new "Star Wars" film. CNET, 2013. Disponível em: https://www.cnet.com/news/r2-d2-fan-builders-hired-for-new-star-wars-film/. Acesso em: 9 nov. 2020.

JENKINS, H. Invasores do texto: fãs e a cultura participativa. Tradução Érico Assis. Nova Iguaçu: Marsupial, 2015. 
LÉVY, P. O que é o virtual? Tradução Paulo Neves. São Paulo: Editora 34, 2017.

MARTIN, G. R. R. A guerra dos tronos: As crônicas de gelo e fogo. Tradução Jorge Candeias. São Paulo: Leya, 2010. v. 1.

MATANGRANO, B. A.; TAVARES, E. Fantástico brasileiro: o insólito literário - do romantismo ao fantasismo. Curitiba: Arte e Letra, 2019.

MENDLESOHN, F. Rhetorics of fantasy. Middletown: Wesleyan University Press, 2008.

NOGUEIRA FILHO, C. A. Dimensões do fantástico e aventuras da tradução em The Lord of the Rings, de J. R. R. Tolkien. 2013. Dissertação (Mestrado em Letras) - Pontifícia Universidade Católica de Goiás, Goiânia, 2013.

ROAS, D. A ameaça do fantástico: aproximações teóricas. Tradução Julián Fuks. São Paulo: Editora Unesp, 2014.

TODOROV, T. Introdução à literatura fantástica. Tradução Maria Clara Correa Castello. São Paulo: Perspectiva, 2010.

TOLKIEN, J. R. R. O bobbit. Tradução Reinaldo José Lopes. Rio de Janeiro: Harper Collins Brasil, 2019.

TOLKIEN, J. R. R. Árvore e folha. Tradução Reinaldo José Lopes. Rio de Janeiro: Harper Collins Brasil, 2020a.

TOLKIEN, J. R. R. O senhor dos anéis. Tradução Ronald Kymrse. Rio de Janeiro: Harper Collins Brasil, 2020b. 